\title{
The City is Flatter: Changing Patterns of Job and Labor Access in Minneapolis-Saint Paul, 1995-2005
}

\author{
David M. Levinson* Bernadette Marion
}

June 1, 2010

\begin{abstract}
This study describes the measurement of accessibility by automobile for the Minneapolis - Saint Paul (Twin Cities) region over the period from 1995 to 2005. In contrast to previous analyses of accessibility, this study uses travel time estimates derived, to the extent possible, from actual observations of network performance by time of day. A set of cumulative opportunity measures are computed with transportation analysis zones (TAZs) as the unit of analysis for 1995 and 2005. Analysis of the changes in accessibility by location over the period of study reveals that, for the majority of locations in the region, accessibility increased over this period, though the increases were not uniform. A "flattening" or convergence of levels of accessibility across locations was observed over time, with faster-growing suburban locations gaining the most in terms of employment accessibility. An effort to decompose the causes of changes in accessibility into components related to transportation network structure and land use (opportunity location) reveal that both causes make a contribution to increasing accessibility, though the effects of changes to the transportation network tend to be more location-specific. Overall, the results of the study demonstrate the feasibility and relevance of using accessibility as a key performance measure to describe the regional transportation system.
\end{abstract}

Keywords: Accessibility; Land Use; Travel Time; Travel Behavior; Twin Cities (Minnesota)

\section{Introduction}

The coevolution of transportation and land use has been established historically in a variety of contexts (Levinson, 2008; Xie and Levinson, 2009b). But coevolution is not just an historical phenomenon, it is something we see everyday as households and firms relocate to

${ }^{*}$ David Levinson, R.P. Braun-CTS Chair of Transportation Engineering, Department of Civil Engineering, University of Minnesota, E-mail: dlevinson@umn.edu, http://nexus.umn.edu 
improve their condition in a changing economic landscape, and as transportation providers restructure and extend transportation networks to better serve their customers. Locators select metropolitan regions to be near activities, things, organizations, and people that are important to them, and they select locations within metropolitan areas for similar reasons, trading off benefits and costs of those locations.

In cities, firms aim to achieve economies of agglomeration and improve productivity and output by locating near customers (other firms and/or households depending on the nature of the firm), suppliers (including their labor force), and even competitors - creating a centripetal force in cities, while trying to reduce costs of land and congestion (which is a centrifugal). Households aim to achieve proximity to their work, shops, and other activities and amenities (also a centripetal force) while simultaneously obtaining more house and lot for the money, producing a centrifugal force on urban regions. This tension between centripetal and centrifugal forces keeps the city from achieving either a maximal density (all activities on a single point) or a minimal densities (all activities spread out evenly across space). However the balance between these two forces changes over time with exogenous changes in other technologies (e.g. vehicles, communication, finance), demographics (e.g. the relative demand for living space varies by life-cycle), socio-economics (e.g. the income or wealth of consumers), and other preferences (e.g. willingness to commute, time scarcity).

The concept of accessibility allows us to measure the efficiency of the city in its primary role, enabling people to reach other people, places, and things. The concept has been welldescribed in the literature (Handy and Niemeier, 1997; Kwan and Weber, 2003; Geurs and van Wee, 2004; Scott and Horner, 2008; Ottensmann and Lindsey, 2008), and in terms of the measure itself, this research constitutes an application rather than a methodological advance. However, this study differs from previous in one important aspect, we use measured rather than modeled accessibility. This means the inputs to the maps presented here are the results of measurements of travel times and delay (supplemented by carefully calibrated models where those measurements lack) rather than the outputs of a regional planning model or based on assumptions of travel speeds based on road classification.

This study further examines the change in the makeup of accessibility in the MinneapolisSaint Paul, Minnesota (Twin Cities) metropolitan area between 1995 and 2005 and tests whether, playing off the title of the recent Thomas Friedman book The World is Flat (Friedman, 2007), the The City is Flatter than it used to be. Minneapolis and Saint Paul arose like many cities in the late 19th and early 20th centuries around the streetcar (Xie and Levinson, 2009a), but ultimately adopted the automobile highway system as the primary means of transportation (Iacono and Levinson, 2009). The period between 1995 and 2005 saw a number of changes in the Twin Cities. Population and employment rose on the order of 1 percent annually, the economy went through one recession associated with the Dot Com bubble, decline in the stock market, and 9/11, and toward the end of the period fuel prices began their rise (ultimately peaking (to date) in 2008). However this is also a period of relative stability in the transportation network. The Twin Cities Interstate system was essentially complete in 1994, and though roads have widened some and new non-freeway links built, these have been relatively minor. There was a relatively sharp increase in traffic in the 
first part of this period, before a leveling off in the later years. Between 1995 and 2005 we see a larger increase in growth in both jobs and workers in the suburbs than the central cities of Minneapolis and St. Paul. This notion of the flattening of the city has been measured in various ways, including e.g. land value (Heikkila et al., 1989), travel times (Gordon, Kumar and Richardson, 1989; Levinson and Kumar, 1994), and analysis of subcenters (McMillen and McDonald, 1998).

The next section describes the data used in this study for both land use and travel times. A travel time matrix is developed and applied to determine the cumulative number of jobs or workers accessible in a given time band. This is followed by a brief methodology on accessibility. The results highlight maps and numeric analyses underlying those maps. We focus on trends from a series of maps within fewer time bands to examine shifts in accessibility more deeply. Specifically, we will look at key commute times including 15, 20, 25, and 30 minute commute-time thresholds. Later, we will narrow the focus to accessibility in years 1995 and 2005 at the 20 minute commute in an attempt to disentangle the those aspects of accessibility associated with different accessibility impacts that may be attributed to land use changes or with changes in the transportation system. The report concludes with implications for policy and the potential for future research in this arena.

\section{Data}

This study aims to measure accessibility for the Twin Cities Metropolitan Area for 1995 and 2005. Thus, a unique challenge the study faces is that it also seeks to generate accessibility measures that take as inputs a matrix of origin-destination (O-D) travel times for the region that are derived from actual traffic data, rather than relying on modeled zone-to-zone travel times. The reasons for this are several. Primary is that modeled travel times (generally the product of regional travel demand models) are not calibrated, planning models aim to match link flows not zone to zone travel times. To that effect, several sources of traffic volume data and link travel time estimates are employed. The components of the travel time matrix include freeway travel time estimates, freeway ramp delay estimates, and arterial travel time estimates. For the most part, freeway travel-time data were collected from freeway loop detector data, ramp delays were modeled using an M/D/1 model structure, and arterial travel-time estimations were generated using a combination of the Skabardonis-Dowling model and and Stochastic User Equilibrium (SUE) updated with counts from Automatic Traffic Recorders (ATR). These data methods are detailed in the Access to Destinations Phase 3 report (Levinson, Marion and Iacono, 2010).

After average travel times were associated with each link in the network, a shortest-path algorithm was used to determine network travel times between each TAZ centroid and all others. The assumption behind this algorithm is that travelers will always try to minimize travel time between their origins and destinations. This is not necessarily the case, because some travelers might value shortest-distance routes even if travel times are slightly longer. Also, in reality the process is iterative, and link speeds can change as volume changes. In this model, the observed speeds are assumed to hold. The routes between each origin and 
Table 1: Regional totals of cumulative opportunity measures in each analysis year.

\begin{tabular}{rrrr}
\hline Year & Population & Employment & Labor \\
\hline 1995 & $2,465,389$ & $1,449,268$ & $1,199,732$ \\
2000 & $2,642,056$ & $1,603,295$ & $1,422,079$ \\
2005 & $2,663,303$ & $1,554,369$ & $1,408,238$ \\
\hline
\end{tabular}

destination with the shortest travel times were calculated in TransCAD 4.8, which uses a version of Dijkstra's algorithm. Separate travel time matrices were constructed for each analysis year and time period. The intrazonal travel times were calculated as half the average travel time to the nearest three adjacent zone centroids.

Data by Transportation Analysis Zone (TAZ) for population, employment and labor were needed for each analysis year, but were not available from any one source or at any one level of aggregation. Data sets were compiled using U.S. Census results from 1990 and 2000, the U.S. Census Bureau Longitudinal Employer-Household Dynamics (LEHD) program, the Census Transportation Planning Package (CTPP), and Metropolitan Council TAZ data from 1990 and 2000. Total population, employment and labor in the Twin Cities metropolitan area in each of the three years as compiled from these sources is shown in Table 1.

The total employment numbers are similar to those given by the Metropolitan Council for the seven counties in 2000 (Metropolitan Council, 2007). The report also discusses a regional decline in the number of jobs after 2000, though it also mentions that by 2005 the region had returned to its peak. A report by the City of Minneapolis does show an increase in both labor and employment form 2000 to 2005, but may only be considering employment of residents of the seven-county area (City of Minneapolis, 2006).

For 2005, employment and labor were available directly at the block level from the LEHD. A main file contained employment information for workers who both live and work within the metropolitan area, and an auxiliary file included those who commute into the area to work but live outside it. For labor, only those workers living within the metro area were considered.

Employment data was available from the Metropolitan Council for both 1990 and 2000 for the 1990 TAZ geography, and averaged to determine 1995 employment. Labor at the block group level for 1995 was calculated by averaging 1990 and 2000 CTPP data. The resulting block-group averages were allocated to blocks using population proportions from 1990 and then aggregated to the TAZ level.

\section{Methodology}

Taken by itself, the travel time matrix generated above measures mobility. The information it contains is enough to determine the speed at which network users can travel from any zone to any other. However, transportation is often described as a derived demand, which 
means that mobility is not an end in itself, but is necessary due to the spatial separation of other activities or objectives (Wachs and Kumagai, 1973). As long as travel is occurring for reasons other than pleasure, the proximity of demanded destinations must be considered along with mobility in order to evaluate the benefits of network performance to the user. In short, the possibility of high-speed travel is of limited use if the distance between origins and destinations is great. Weighting mobility by the number of opportunities it presents to arrive at accessibility can help direct investment in network improvements not merely toward where speed will be increased the most, but to where the increased speed will provide the greatest improvement in terms of access to desired destinations. Where mobility improvements respond to a derived demand, increased accessibility addresses a more basic need.

Accessibility can be thought of as the potential opportunity for interaction (Hansen, 1959). In this analysis, cumulative opportunity measures are calculated as total numbers of jobs, residents and workers reachable from each point in a given time period. This measure was chosen because it is spatially continuous and suitable for creating maps to compare changes in accessibility across the region. Maps showing extents of equal accessibility can also be created, similar to topographic contour maps showing lines of equal elevation. Alternative measures could be either gravity- or utility-based. Gravity measures introduce an additional complication in that an appropriate function of distance must be chosen. Utility is a difficult concept to quantify, because individual residents place widely varying value on access to different things.

The Hansen accessibility measure is traditionally defined as:

$$
A_{i}=\sum_{j=1}^{n} O_{j} f\left(C_{i j}\right)
$$

where:

$A_{i}=$ accessibility from a zone $(i)$ to the considered type of opportunities $(j)$

$O_{j}=$ opportunities of the considered type in zone $j$ (e.g., employment, shopping, etc.)

$C_{i j}=$ generalized (or real) time or cost from $i$ to $j$

$f\left(C_{i j}\right)=$ Impedance function (exponential or power functions are most often used)

Here we use a cumulative opportunities function, which defines $f\left(C_{i j}\right)=1$ if $C_{i j}<$ $T$ and 0 otherwise. The threshold $\mathrm{T}$, indicating the time for which we will compute the number of activities that can be reached, varies from 5 minutes to 60 minutes depending on the map, allowing us to examine both long and short trips. The cumulative opportunities function satisfies five criteria (Krizek and Levinson, 2008): Cumulative, Comparable, Clear, Comprehensive, and Calculable, some of which escape other more complicated measures.

\section{Accessibility to Jobs and Workers}

The changes in accessibility from 1995 to 2005 are described in this section. The detailed results are illustrated in Figure 2 for accessibility to jobs and to workers by auto within 20 minutes for 1995 and 2005 for the AM peak period. Other results can be found in Levinson, 
Marion and Iacono (2010). The most striking trend is that accessibility by automobile increases almost everywhere over this period. The change in land use and densification of activities outweigh any increase in congestion. While in 1995 only one zone could reach more than one million jobs within 20 minutes, by 2005 that number had increased to 20. Within 30 minutes, well more than half the population of the region can reach over one million jobs, while within 45 minutes, almost everyone in the Twin Cities region can reach more than one million jobs by auto. All of this is not to say there were no accessibility losses, as there were some, but they were outweighed by gains.

When the travel times are low, accessibility is concentrated in the urban centers of Minneapolis and Saint Paul. As the cumulative opportunity travel time thresholds increase, corridors of relatively high accessibility become evident along major highways, especially I-35W south of downtown Minneapolis. Downtown Saint Paul diminishes in accessibility compared to other points in the region once the radius is increased to a 25-minute travel time. Although it is a dense cluster of opportunities within a five-to-ten-minute trip, it is relatively isolated from other development centers such as the I-494 corridor in the southsouthwest part of the region. When opportunities within a 30-minute reach are considered, the concentrations along highway routes are no longer obvious, and the gaps between major routes begin to fill in. From 35 to 60 minutes, accessibility gains radiate outward from a point in the center of the region closer to downtown Minneapolis than downtown Saint Paul.

In general, the southern portion of the region has access to more destinations in shorter travel times than the north. Once 40 minutes are allowed for travel, residents of all but the most rural zones have access to at least 100,000 jobs. The least accessible zones are in the southwest corner of the region, but this should be qualified by noting that more jobs in locations outside the seven counties may be reachable from these zones. Other points of interest due to their effects on accessibility are areas that may be near or adjacent to the mainlines of high-speed routes but some distance away from the nearest onramp. An example of this is the area south of Highway 62 between I-35W and Highway 77. Another factor that affects accessibility adversely that can be seen in the maps appears in places with large gaps between river crossings.

Also of note is that the accessibility gains at the edge of region outweigh those in the center. The suburbs are more accessible in 2005 than they were in 1995, while changes in the already highly accessible center city have been much more modest. Overall person-weighted accessibility by county is given in Figure 1,

\section{$5 \quad$ Standard Deviational Ellipse Analysis (SDE)}

Although the previous analysis of the 20 minute commute-time threshold reveals many trends, including those that suggest that the city is indeed getting flatter, there is still an opportunity to further generalize accessibility outcomes for trend analysis. The Standard Deviational Ellipse (SDE) measure complements our discussion of accessibility differences across space (Lefever, 1926; Yuill, 1971; Eck et al., 2005). The tool is most commonly used to identify hot spots of crime events; however it used in numerous other types of studies as a 
method for spatially descriptive exploration. Both the dispersion and orientation of the dispersion of events are described by the generated ellipse. Thus, SDE is particularly effective at capturing the directionality bias of the location of events in any direction including intermediate compass directions around the mean center. For a set of geographical coordinates, the ellipse is calculated by first finding the mean center of events, which is located at the intersection of the average of $\mathrm{X}$ coordinate values and the average of $\mathrm{Y}$ coordinate values. The length of each axis is defined by the standard deviation of the distribution of values from the mean respectively. A higher standard value implies a larger dispersion of events on that axis. The ratio of the two axes yield a measure of circularity. The circularity of the ellipse is also useful for understanding whether the reach of accessibility is, in a crude way, flat. A low degree of circularity implies that the location of events described by the (SDE) are tightly dispersed along a directional path. So, for example, a measure of circularity allows the user to ascertain whether high accessibility events are associated with any one particular transportation corridor. When considering all of these factors, SDE appears an ideal means by which to understand the distribution of accessibility inequality within the urban system.

Figure 3 shows the SDE for access within 20 minutes to 100,000 and 500,000 jobs and workers. As can be seen from these figures, the city is indeed getting flatter at the 20 minute level, the 2005 SDE is larger, and almost completely encloses each 1995 ellipse.

\section{Job / Worker Balance}

The importance of job/worker balance for commuting has been debated in the literature (Cervero, 1989; Giuliano and Small, 1993; Cervero, 1996; Levinson, 1998). Almost everywhere, employment remains much more concentrated than labor. Recognizing that, at the metropolitan level, the number of jobs essentially equals the number of workers, access to jobs is much more highly peaked in city centers than access to labor is.

We find in the Twin Cities that peak locations are very close. We also see that over this period, the center of gravity of employment has moved westward (in the south-southwest direction), while the center of gravity of labor has moved less so. Labor has continued to suburbanize, more so in the directions North and South of Minneapolis, and less directly due west. A ratio of jobs to labor (which equals 1.0 at the regional level) shows where job access exceeds labor access, and where the converse is true. Overall the region is becoming more balanced at the longer time bands (though less balanced locally).

Figure 4 shows job to worker ratio at 15 and 30 minute timebands for 1995 and 2005 . The areas in dark red indicate areas with the greatest ratio of jobs to workers. These areas tend to surround downtown, but have migrated from 1995 to 2005. The areas in dark blue indicate the areas with the lowest ratio, which tend to be at the edge of the region. As the timeband increases, areas are in greater balance and fewer traffic zones show extreme values. The general pattern is similar for the two years. Considering a 30 minute bandwidth balance is significantly increased between 1995 and 2005.

Use of job/worker accessibility ratios (rather than job/worker ratios at municipal levels) may still have a role in planning in explaining important difference in commute times (Levin- 
son, 1998; Clark and Kuijpers-Linde, 1994; Sultana, 2002), though the flattening of the ratio may indicate that the market is itself performing a type of arbitrage between imbalanced areas to address this issue.

\section{Causes of Accessibility Change}

What caused the accessibility changes we see? To what extent is it due to changes in the transportation network (either added capacity or changes in congestion level), or due to changes in land use? A series of experiments are conducted to disentangle those changes.

First, as we observe in Figure 5, segments colored red indicate faster freeway speeds in 2005 than 1995 and blue indicates slower speeds in 2005. The pattern is mixed. Roads with improvements show significantly faster speeds, while roads under construction or in areas with fast growth (especially in the southwest) show slower speeds. Note that the most widely cited longitudinal study, (Schrank and Lomax, 2009), finds that congestion in the Twin Cities region increased, with a travel time index (the ratio of congested to freeflow travel time) rising from 1.17 to 1.26., and annual delay per peak traveler rising from 31 hours per year in 1995 to 43 hours in 2005.

We consider what would have happened had either travel times or land use not changed. Recall Figure 2 shows accessibility to jobs in 1995 using 1995 land use and networks (top left) and in 2005 using a 2005 land use and network (top right). Figure 6 shows (a) a scenario using 1995 land use and 2005 travel times, and (b) a difference comparing Figure ( 2 (top right) ) - (a). The greatest increase in accessibility to jobs because of land use changes is found in the western suburbs of the Twin Cities, especially the southwest, along the I-494 beltway, while some decreases are shown in certain zones in the eastern part of the metropolitan region. The figure then examines what would have happened to accessibility to jobs had the networks not changed. Let (c) be a scenario using 2005 land use and 1995 travel times, and $(\mathrm{d})$ the difference (Figure ( 2 (top right)) - (c)). Access to jobs increased due to capacity enhancements in much the same places as accessibility to workers (not shown) (the northeast, the far west, and the southeast). It declines in the same places as well (the northeast and the southwest), with small increases in the center city.

\section{Conclusions}

This study describes the process and outcomes resulting from an effort to measure changes in regional accessibility by auto during the period from 1995 to 2005. In contrast to the earlier research efforts that make use of accessibility metrics, this project is unique in that it derives time-dependent measures of accessibility that use as inputs travel time estimates based (to the extent possible) on directly measured travel times or observed link flows, as opposed to modeled flows. These measures are then tracked over time at the zone level to identify the direction and magnitude of accessibility changes.

One key finding of this study is that nearly all parts of the Minneapolis-Saint Paul region 
became more accessible in absolute terms over the period under study. The greatest growth occurred in faster-growing, suburban parts of the region. This trend was observed when measuring access to both jobs and workers, suggesting that between 1995 and 2005 both households and employers were decentralizing. It should be noted this result while true for Minneapolis, may not be true in every US city for all periods, e.g. Helling (1998) found declining accessibility in Atlanta.

Moreover, this process has tended to reduce disparities in levels of accessibility between locations over time, leading to a "flattening" of accessibility across the region. Evidence of broad-based accessibility gains due to urban restructuring is reinforced by the fact that by most standard measures of network performance, traffic congestion was worsening. Locational responses by households and firms, particularly the clustering of activities in certain locations, more than offset the negative impact of the deterioration of network performance. The flattening or convergence of accessibility across locations within the region is corroborated by the additional evidence of job/worker balances improving in most locations, and by the increasing roundness of the standard deviational ellipses describing the distribution of accessibility across locations within the within the region.

Further investigation into the relative causes of these changes reveals that both changes in the location of opportunities and the structure of the transportation network contributed to the increase in accessibility observed throughout the region. Holding either land use or network travel times constant at their 1995 values allows the decomposition of accessibility changes into these two components. Densification of existing centers of activity, primarily around the region's beltway, led to increased job access in many such locations. Likewise, some limited network improvements (i.e. TH 169, 212 and 610) improved job access near the locations where they took place. The southwestern part of the region was a major beneficiary of these improvements. Only modest declines in accessibility as a result of land use and network changes were observed, and these tended to be limited to a handful of central city locations.

The results of this study help to demonstrate the value of accessibility as a measure of transportation performance. Accessibility measures provide a more complete picture of system performance by synthesizing the effects of changes to both transportation networks and the destinations they serve. In the absence of information on the location of opportunities, one may have concluded that most locations within the Twin Cities became less accessible over the period from 1995 to 2005. Our results have led largely to the opposite conclusion. Within cities, it is access to desired destinations that households value, and hence it is important to select measures that reflect how well these needs are being served. Our findings make a strong case for the inclusion of accessibility as a critical component of performance evaluation for transportation engineers and planners.

\section{Acknowledgments}

We would like to thank John Hourdos and Ted Morris from the Minnesota Traffic Observatory for their assistance with developing the arterial travel time estimates, and for providing 
information on the collection of signal timing data to augment arterial link travel times. We would also like to thank Hui Xiong for providing valuable information on the process of updating arterial link volumes in the absence of reliable traffic count data. Michael Iacono, Jason Junge, Shu Hong, Pavithra Parthasarathi, Shanjiang Zhu, and Carlos Carrion also assisted on this project. The project was funded by the Minnesota Department of Transportation. The authors are solely responsible for content. 


\section{References}

Cervero, R. 1989. "Jobs-housing balancing and regional mobility." Journal of the American Planning Association 55(2):136-150.

Cervero, R. 1996. "Jobs-Housing Balance Revisited: Trends and Impacts in the San Francisco Bay Area." Journal of the American Planning Association 62(4).

City of Minneapolis. 2006. "Minneapolis Trends 2000-2005." City of Minneapolis Department of Community Planning and Economic Development, Minneapolis, MN.

Clark, W.A.V. and M. Kuijpers-Linde. 1994. "Commuting in restructuring urban regions." Urban Studies 31(3):465.

Eck, JE, S. Chainey, JG Cameron, M. Leitner and RE Wilson. 2005. "Mapping crime: Understanding hot spots.".

Friedman, T.L. 2007. The world is flat: A brief history of the twenty-first century. Douglas \& McIntyre.

Geurs, K.T. and B. van Wee. 2004. "Accessibility evaluation of land-use and transport strategies: review and research directions." Journal of Transport Geography 12(2):127140.

Giuliano, G. and K.A. Small. 1993. "Is the journey to work explained by urban structure?" Urban Studies 30(9):1485.

Gordon, P., A. Kumar and H.W. Richardson. 1989. "The influence of metropolitan spatial structure on commuting time." Journal of Urban Economics 26(2):138-51.

Handy, S.L. and D.A. Niemeier. 1997. "Measuring accessibility: an exploration of issues and alternatives." Environment and planning A 29:1175-1194.

Hansen, Walter G. 1959. "How accessibility shapes land use." Journal of the American Planning Association 25:73-76.

Heikkila, E., P. Gordon, J.I. Kim, R.B. Peiser, H.W. Richardson and D. Dale-Johnson. 1989. "What happened to the CBD-distance gradient? Land values in a policentric city." Environment and Planning A 21(2):221-232.

Helling, A. 1998. "Changing intra-metropolitan accessibility in the US: Evidence from Atlanta." Progress in Planning 49(2).

Iacono, M.J. and D.M. Levinson. 2009. "Predicting Land Use Change." Transportation Research Record: Journal of the Transportation Research Board 2119(-1):130-136.

Krizek, Kevin and David Levinson. 2008. "Access for performance." Paper presented at 2010 Transportation Research Board conference, Washington, DC. 
Kwan, M.P. and J. Weber. 2003. "Individual Accessibility Revisited: Implications for Geographical Analysis in the Twenty-First Century." Geographical Analysis 35(4):341-354.

Lefever, D.W. 1926. "Measuring geographic concentration by means of the standard deviational ellipse." The American Journal of Sociology 32(1):88-94.

Levinson, D. 2008. "Density and dispersion: the co-development of land use and rail in London." Journal of Economic Geography 8(1):55.

Levinson, David M., Bernadette Marion and Michael Iacono. 2010. Access to Destinations , Phase 3: Measuring Accessibility by Automobile. Research report MN/RC-2010-XX Center for Transportation Studies, University of Minnesota Minneapolis, MN: . Report No. X in the Access to Destinations series.

Levinson, D.M. 1998. "Accessibility and the journey to work." Journal of Transport Geography $6(1): 11-21$.

Levinson, D.M. and Ajay Kumar. 1994. "The rational locator: why travel times have remained stable." Journal of the american planning association 60(3):319-332.

McMillen, D.P. and J.F. McDonald. 1998. "Suburban subcenters and employment density in metropolitan Chicago." Journal of Urban Economics 43(2):157-180.

Metropolitan Council. 2007. "Employment in the Twin Cities Region, 2000-2006." Metropolitan Council Publication No. 74-07-010, Saint Paul, MN.

Ottensmann, J.R. and G. Lindsey. 2008. "A use-based measure of accessibility to linear features to predict urban trail use." Journal of Transport and Land Use 1(1):41-63.

Schrank, D. and T. Lomax. 2009. The 2009 urban mobility report. Technical report Texas Transportation Institute, College Station, Texas.

Scott, D.M. and M. Horner. 2008. "The role of urban form in shaping access to opportunities." Journal of Transport and Land Use 1(2):89-119.

Sultana, S. 2002. "Job/housing imbalance and commuting time in the Atlanta metropolitan area: exploration of causes of longer commuting time." Urban Geography 23(8):728-749.

Wachs, Martin and T. Gordon Kumagai. 1973. "Physical accessibility as a social indicator." Socio-economic Planning Science 7(5):437-456.

Xie, F. and D. Levinson. 2009a. "How streetcars shaped suburbanization: a Granger causality analysis of land use and transit in the Twin Cities." Journal of Economic Geography

Xie, F. and D. Levinson. 2009b. "Modeling the Growth of Transportation Networks: A Comprehensive Review." Networks and Spatial Economics 9(3):291-307. 
Yuill, R.S. 1971. "The Standard Deviational Ellipse; An Updated Tool for Spatial Description." Geografiska Annaler. Series B, Human Geography 53(1):28-39. 


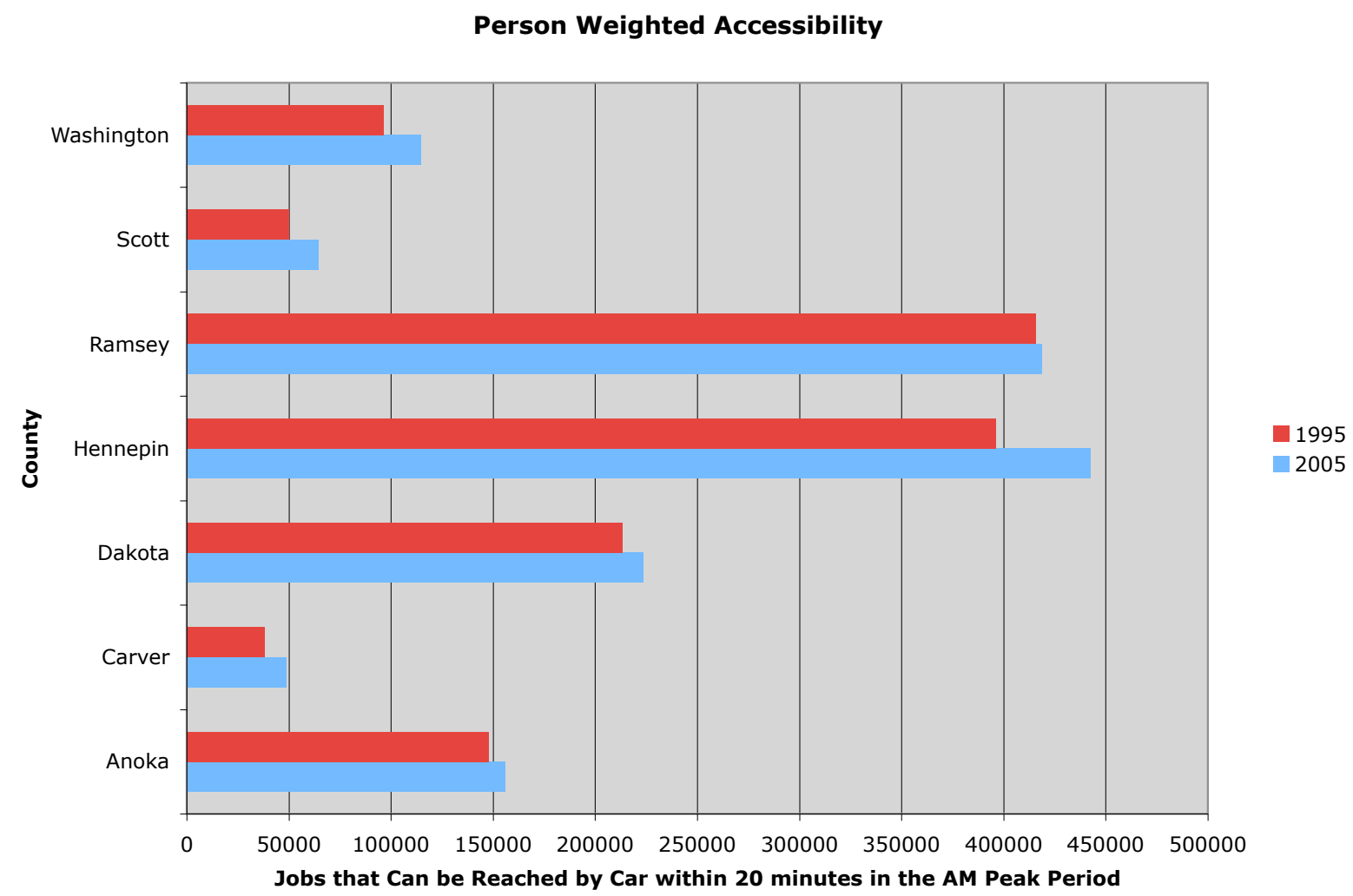

Figure 1: Person-weighted accessibility to jobs by county. Person-weighted accessibility $(A)$ is the weighted average of accessibility by zone, where the weight is the population or number of workers $\left(W_{i}\right)$ in that zone experiencing that level of accessibility. This can be computed for the entire region or any sub-region. $A=\frac{\sum_{i=1}^{n} A_{i} W_{i}}{\sum_{i=1}^{n} W_{i}}$ 


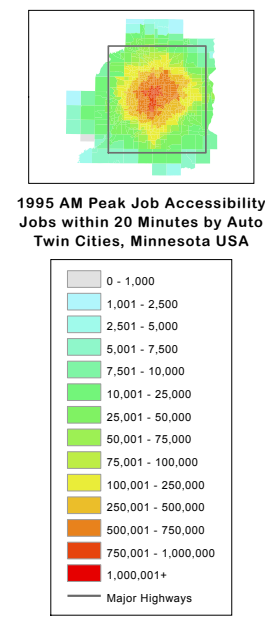

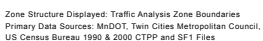

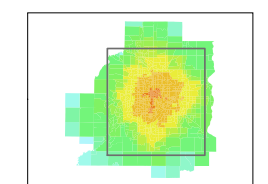

1995 AM Peak Labor Accessibility Labor within 20 Minutes by Auto

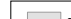

$\square^{0-1,000}$

$\square^{2}, 001 \cdot 2,500$
$2,501 \cdot 5,000$

$2,501-5,000$
$5,001-7,500$

$7,501 \cdot 10,000$
$10,001 \cdot 25,000$

25,001 - 50,000

$50,001-75,000$

$75,001-100,000$
$100,001-250,000$

$1,000,1,000$

Major Highway


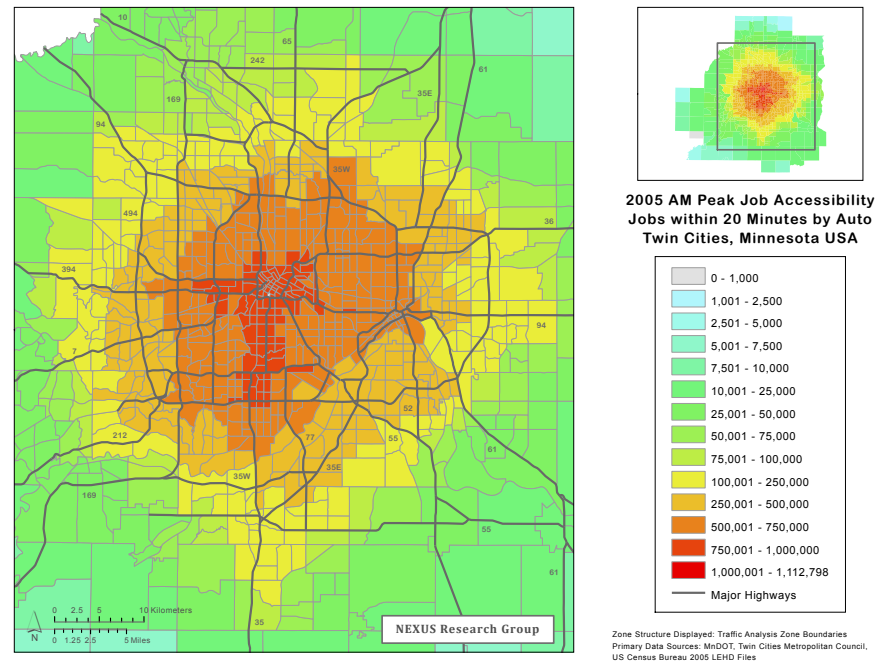

2005 AM Peak Job Accessibility Jobs within 20 Minutes by Aut

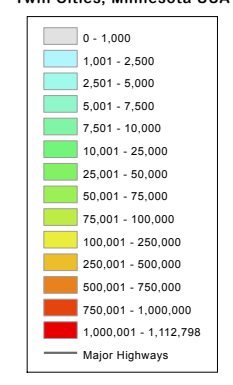

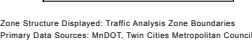



2005 AM Peak Labor Accessibility Labor within 20 Minutes by Auto
Twin Cities, Minnesota USA
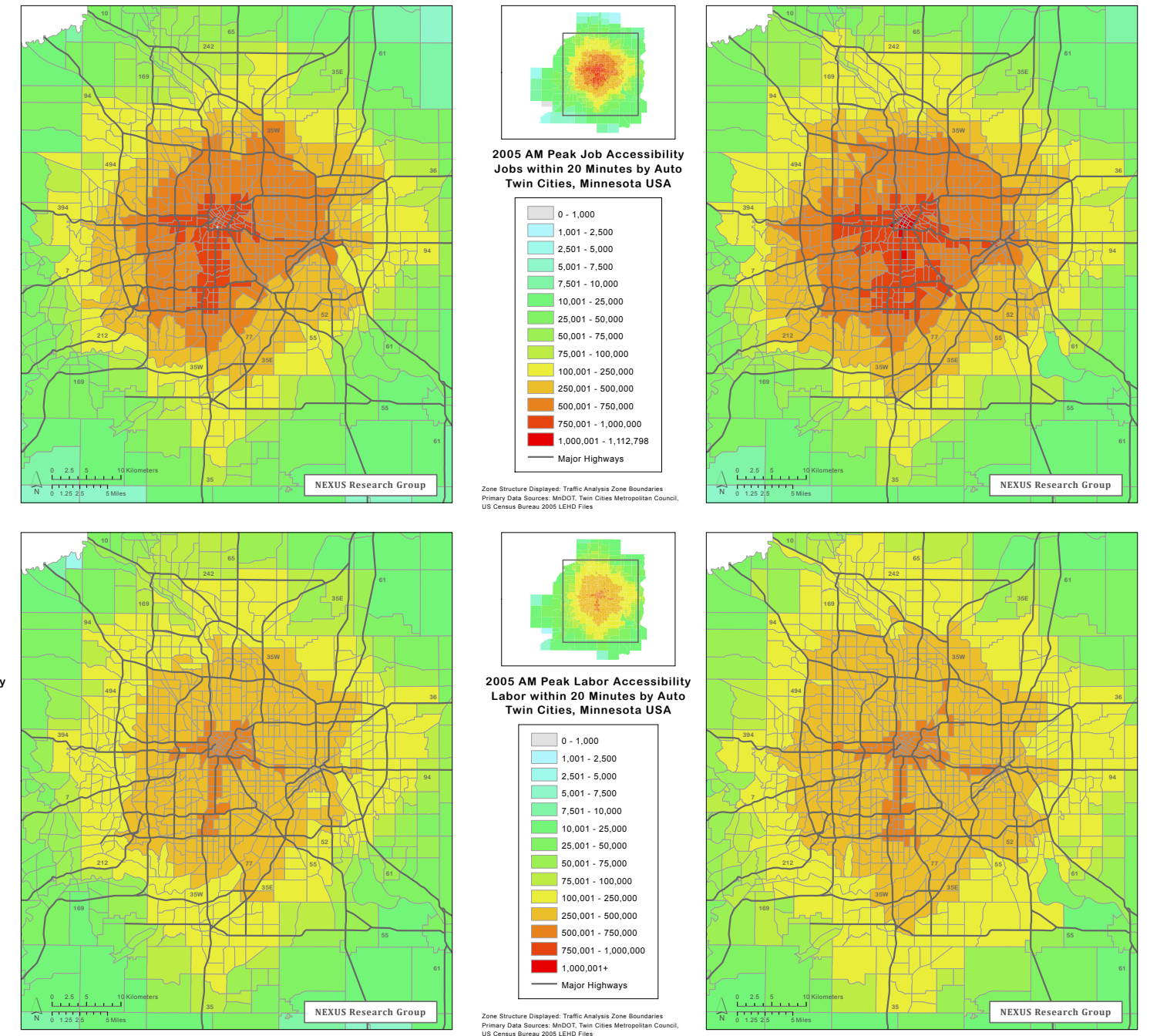

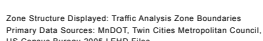

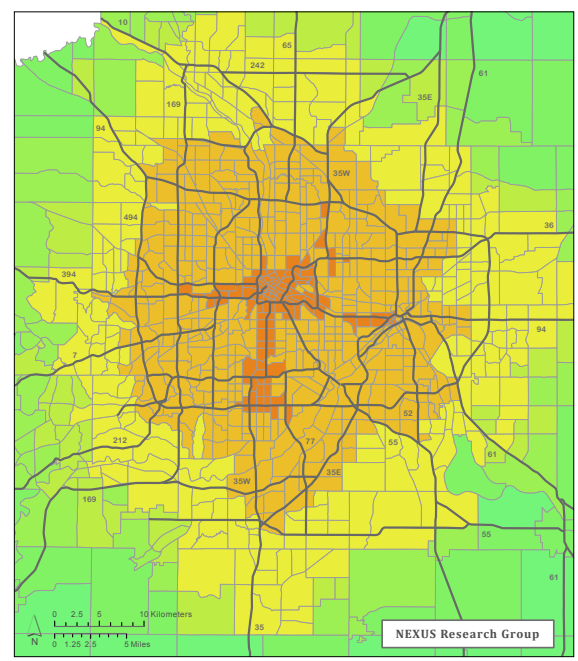

Figure 2: Jobs and Labor accessible within 20 minutes 

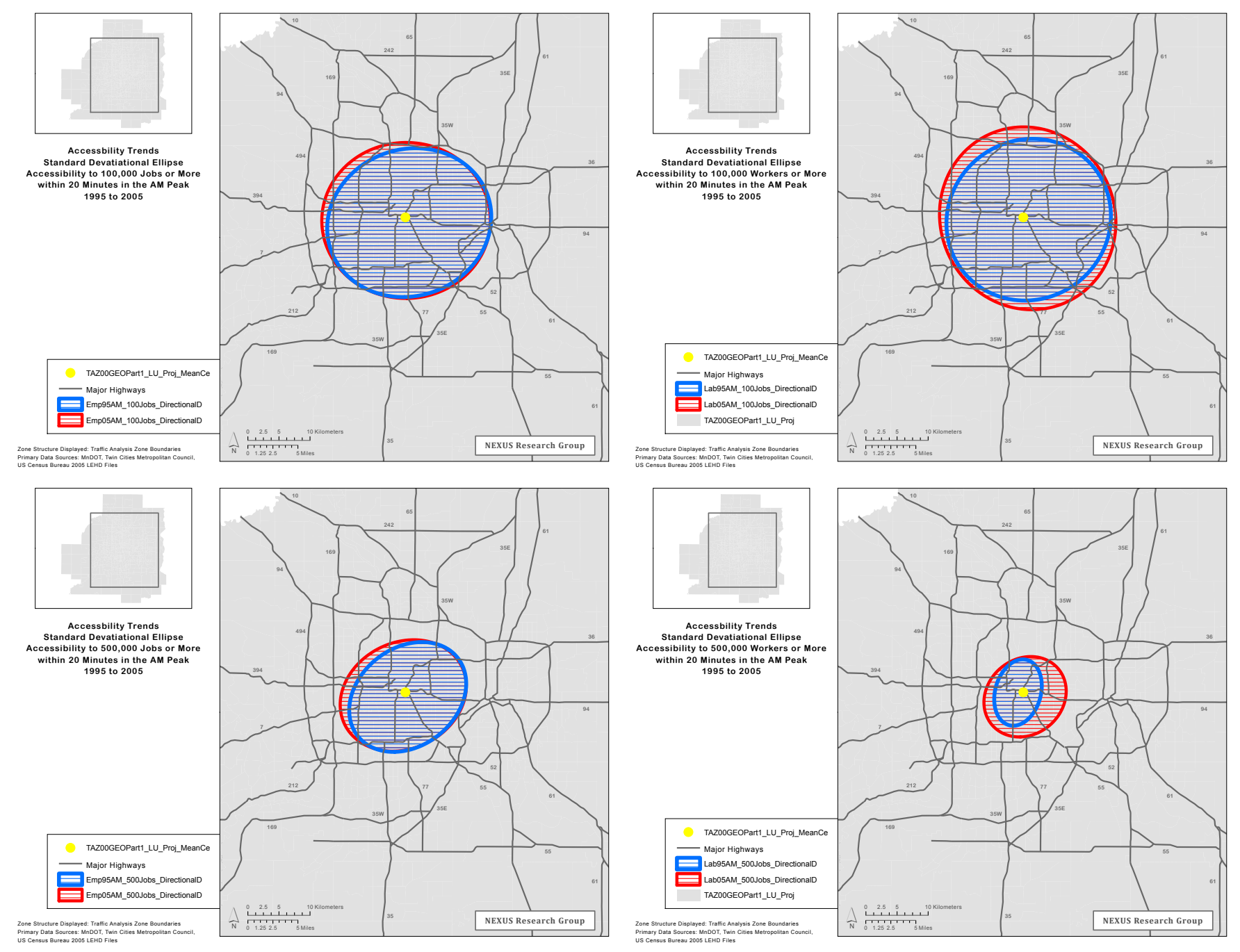

Figure 3: Standard deviational ellipse for access within 20 minutes to 100,000 and 500,000 jobs and workers (2005 and 1995) in the AM peak period 


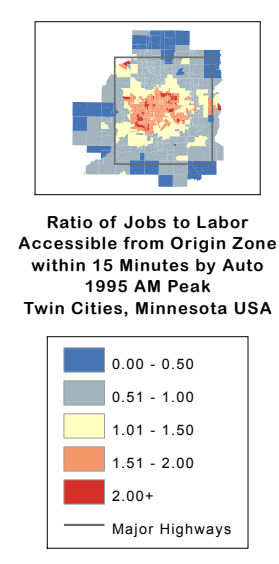

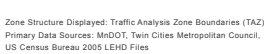

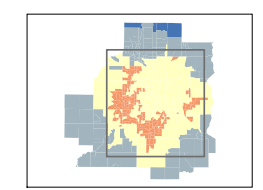

Ratio of Jobs to Labor Accessible from Origin Zon within 30 Minutes by Auto 1995 AM Peak
Twin Cities, Minnesota USA

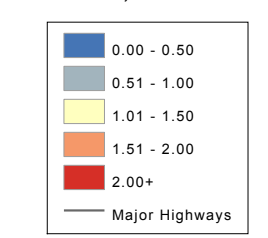

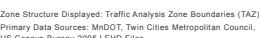
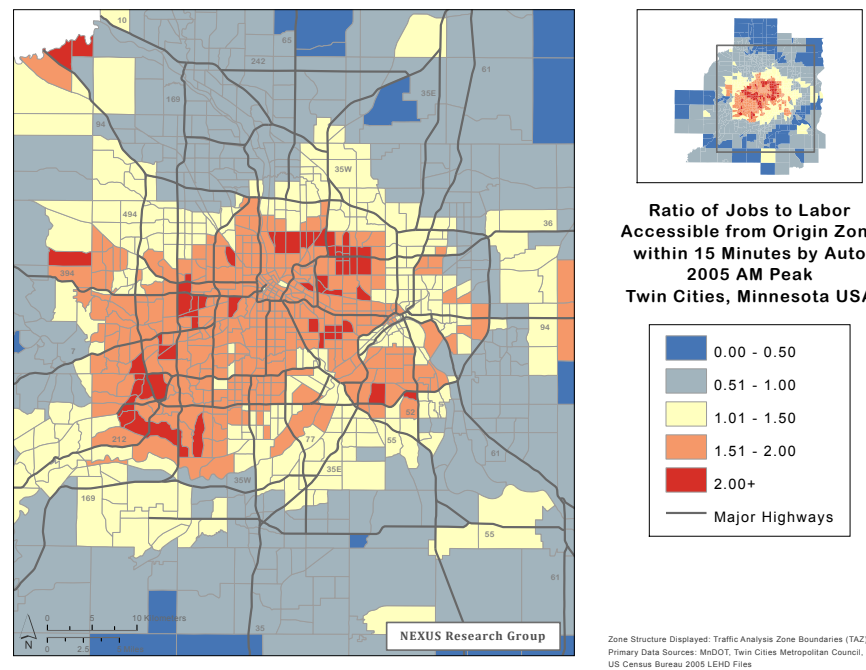

Ratio of Jobs to Labor Accessible from Origin Zone within 15 Minutes by Auto 2005 AM Peak Twin Cities, Minnesota USA

$0.00-0.50$

$0.51-1.00$

$\square 1.01-1.50$

$1.51-2.00$

$2.00+$

- Major Highways
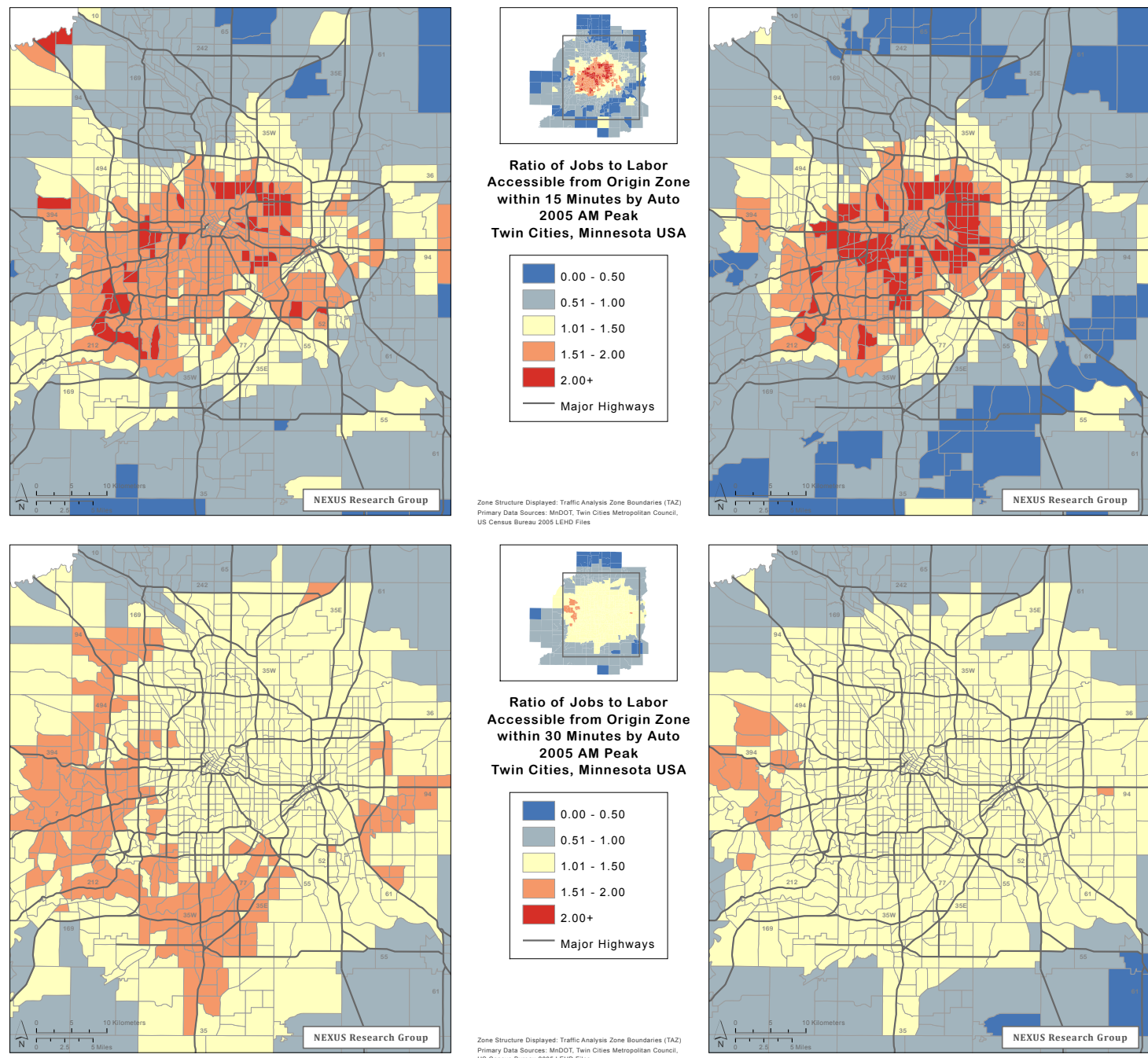

Ratio of Jobs to Labor Accessible from Origin Zone within 30 Minutes by Auto Twin Cities, Minnesota USA

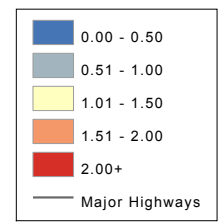

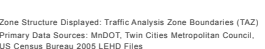

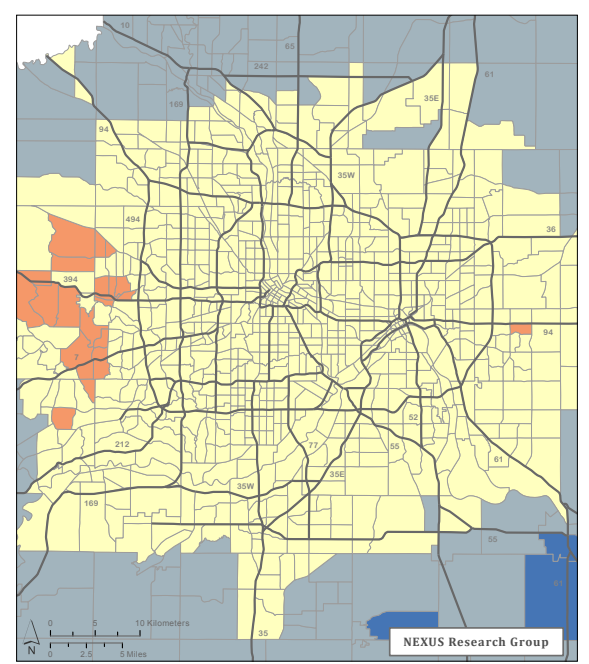

Figure 4: Job / worker ratio at 15 and 30 minutes 

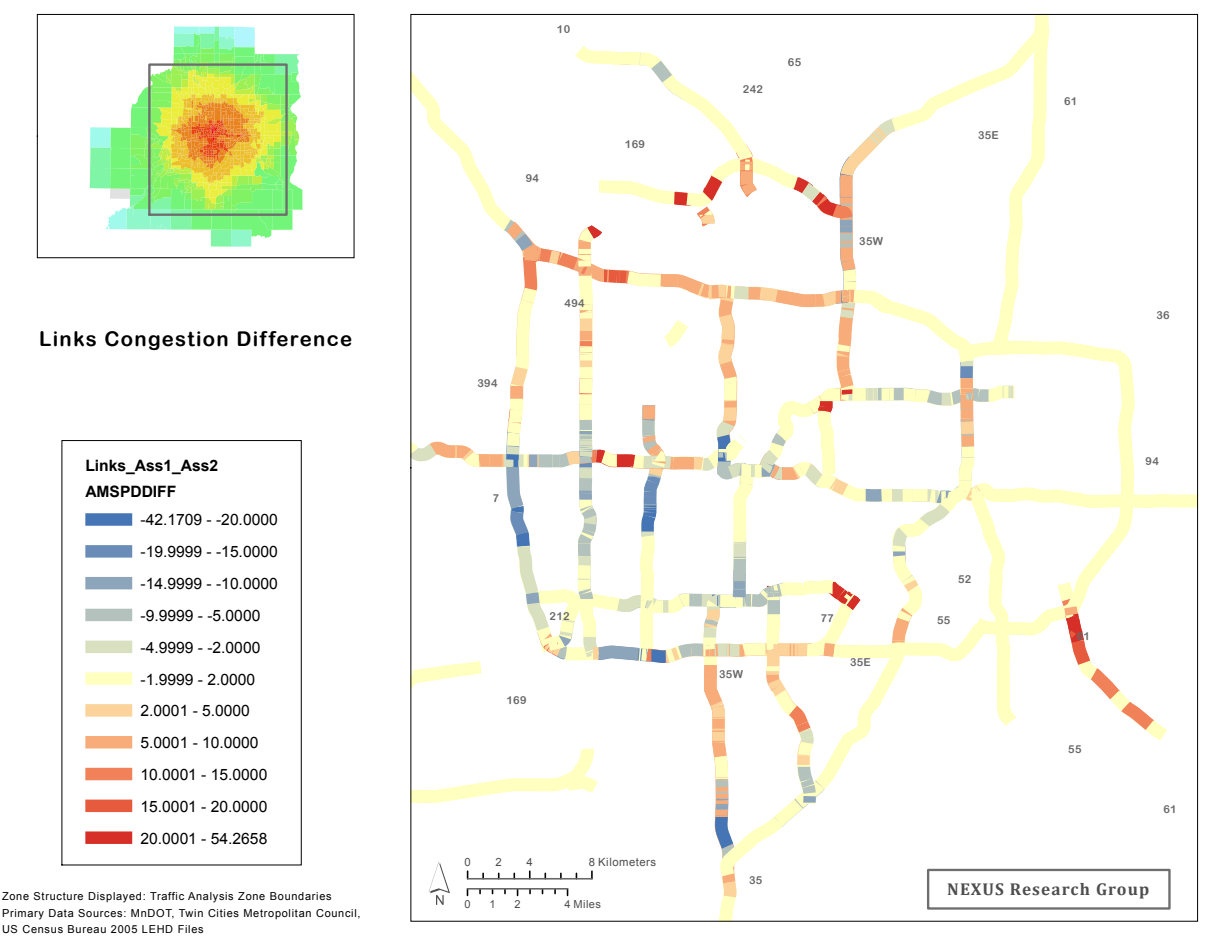

Figure 5: Changes in highway speeds in the AM peak period 

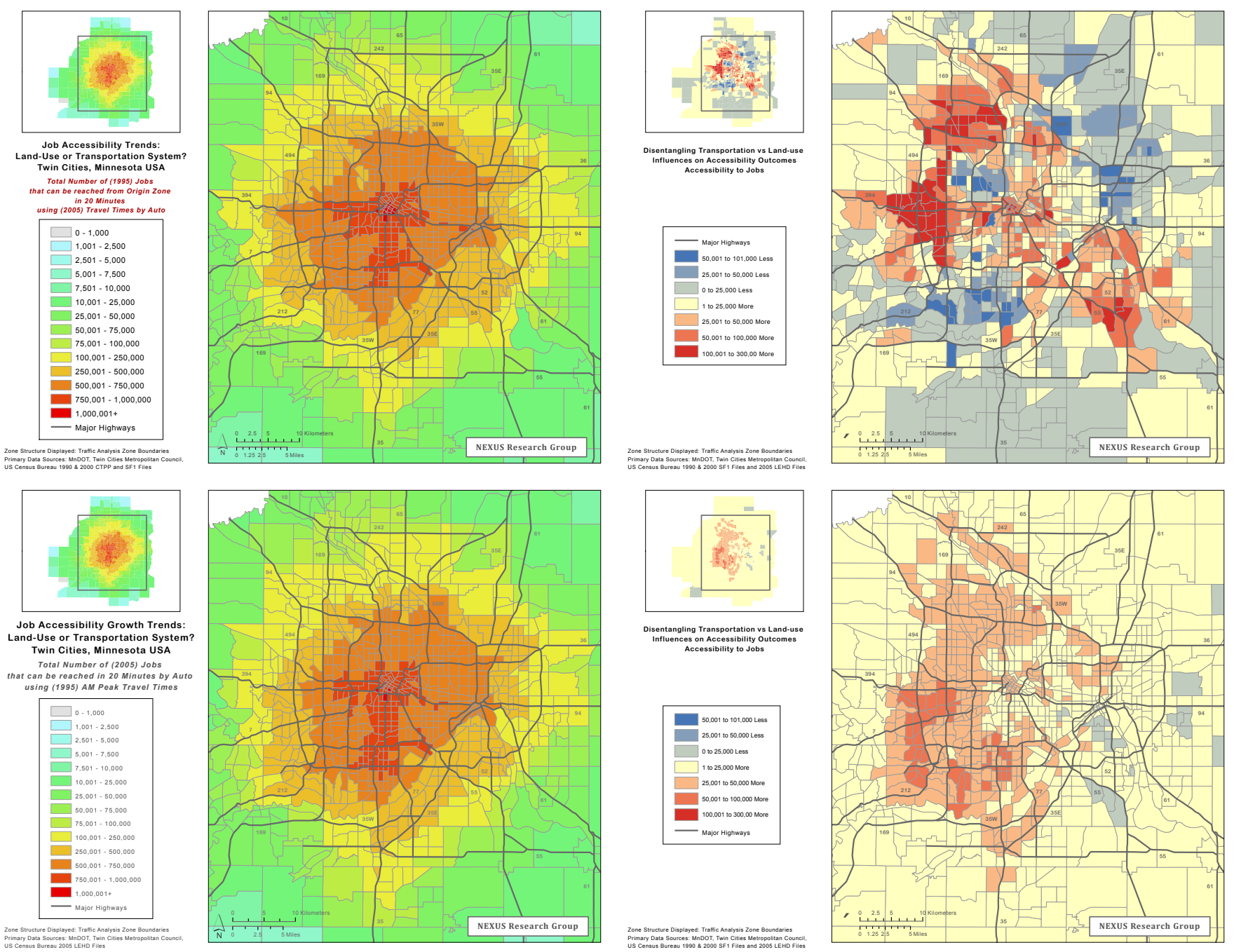

Figure 6: Access to jobs land use and transportation scenarios and differences. The figures are (a) A scenario using 1995 land use and 2005 travel times, (b) a difference comparing measured 2005 accessibility (Figure 2 (bottom)) - (a), (c) a scenario using 2005 land use and 1995 travel times, and (d) the difference of measured accessibility and (Figure 2 (bottom) - (c)). 